\title{
PENGARUH PENGGUNAAN MODEL PEMBELAJARAN PROBLEM BASED LEARNING (PBL)-STUDY HISTORY SHEET (SHS) BAHAN AJAR BERBASIS GREEN CHEMISTRY PADA MATERI KELARUTAN DAN HASIL KALI KELARUTAN TERHADAP PRESTASI BELAJAR BELAJAR SISWA KELAS XI SMA NEGERI 10 MALANG
}

\author{
Elinira Subandi ${ }^{\mathrm{a}}$, Ridwan Joharmawan ${ }^{\mathrm{b}}$, Aman Santoso ${ }^{\mathrm{c}}$ \\ a,b,cJurusan Kimia FMIPA Universitas Negeri Malang
}

\begin{abstract}
Abstrak - Penelitian ini bertujuan untuk mengetahui pengaruh penggunaan model pembelajaran Problem Based Learning (PBL)-Study History Sheet (SHS) bahan ajar berbasis Green Chemistry pada materi kelarutan dan hasil kali kelarutan terhadap prestasi belajar belajar siswa kelas XI SMA Negeri 10 Malang. Rancangan penelitian yang digunakan adalah quasy experimental design dengan post test only control group design. Prestasi belajar kognitif siswa kelas dengan perlakuan problem based learning (PBL)-study bistory sheet (SHS) bahan ajar berbasis green chemistry lebih tinggi $(\bar{x}=79)$ dibandingkan dengan prestasi belajar kognitif siswa pada kelas dengan perlakuan model pembelajaran problem based learning $(\bar{x}=76)$. Demikian juga prestasi belajar afektif siswa khususnya sikap peduli pada masalah pencemaran air kelas dengan perlakuan problem based learning (PBL)-study history sheet (SHS) bahan ajar berbasis green chemistry lebih tinggi daripada kelas dengan perlakuan model pembelajaran problem based learning. Hal ini dibuktikan dengan data persentase rata-rata sikap kepedulian siswa pada masalah pencemaran air kelas dengan perlakuan model pembelajaran problem based learning sebesar $90 \%$, sedangkan kelas dengan perlakuan problem based learning (PBL)-study history sheet (SHS) bahan ajar berbasis green chemistry sebesar 92\%. Sehingga dapat disimpulkan bahwa ada pengaruh penggunaan model pembelajaran Problem Based Learning (PBL)-Study History Sheet (SHS) bahan ajar berbasis Green Chemistry pada materi kelarutan dan hasil kali kelarutan terhadap prestasi belajar belajar siswa kelas XI SMA Negeri 10 Malang.
\end{abstract}

Kata kunci: Problem Based Learning (PBL), Study History Sheet (SHS),Green Chemistry, Prestasi Belajar

\begin{abstract}
This research goal was understanding the effect of problem based learning (PBL)-study history sheet (SHS) learning model with green chemistry teaching material based in solubility and solubility product constant on student learning achievement of sma negeri 10 malang eleventh grade. The research design was quasy experimental with post test only control group design. The cognitive learning achivement of based learning (PBL)-study history sheet (SHS) learning model with green chemistry teaching material class is higher $(\bar{x}=79)$ than learning achivement of problem based learning class $(\bar{x}=76)$. As well as the affective learning achivement especially the water pollution caring attitude for problem based learning class was $90 \%$, while based learning (PBL)-study history sheet (SHS) learning model with green chemistry teaching material class was $92 \%$. So the conclusion, there were implementation effect of problem based learning (PBL)-study history sheet (SHS)learning model with green chemistry teaching material based in solubility and solubility product constant on student learning achievement of 10 public senior high school of Malang in eleventh grade.
\end{abstract}

Keywords: Problem Based Learning (PBL), Study History Sheet (SHS), Green Chemistry, learning achivement 


\section{PENDAHULUAN}

Kurikulum KTSP menggunakan istilah pendidikan berkarakter yang bertujuan agar siswa dapat dengan nyata memaknai pembelajaran. Karakter yang dimaksud dalam KTSP adalah peduli lingkungan. Peduli lingkungan yang dimaksud merupakan sikap dan tindakan yang selalu berupaya mencegah kerusakan pada lingkungan alam di sekitarnya dan mengembangkan upaya-upaya untuk memperbaiki kerusakan alam yang sudah terjadi (Mundilarto, 2013:157). Ilmu kimia merupakan bagian dari ilmu sains yang berisi sekumpulan konsep, teori dan hukum. Konsep-konsep pada ilmu kimia adalah konsep abstrak sehingga banyak siswa beranggapan bahwa kimia adalah salah satu pelajaran yang sulit dipahami dan membosankan (Mukaromah, dkk., 2014: 42). Guru perlu menciptakan suasana kelas dan proses pembelajaran yang menyenangkan dan tidak membosankan sehingga siswa akan terlibat aktif selama proses pembelajaran berlangsung. Pembelajaran dengan pendekatan lingkungan menghapus kejenuhan dan menciptakan peserta didik yang cinta lingkungan. Kesadaran itulah yang kemudian disebut "Kimia Hijau" (green chemistry). Konsep ini kemudian dipaparkan ke dalam 12 prinsip yang dikeluarkan oleh Oxford University press (Hjeresen, 2000).

Metode pembelajaran yang menghubungkan permasalahan dikehidupan nyata siswa untuk dievaluasi secara langsung dapat memberikan hasil yang lebih efektif untuk pendekatan green chemistry ini. Penerapan ke-12 prinsip green chemistry dalam pembelajaran membutuhkan sebuah metode mengajar sebagai strategi pembelajaran agar green chemistry dapat dipelajari dengan baik oleh siswa. Pemilihan dan penentuan strategi pembelajaran ini diharapkan mampu membantu pencapaian tujuan dari pendekatan green chemistry yang diinginkan. PBL (Problem Based Learning) merupakan model pembelajaran yang berorientasi pada kerangka kerja teoritik konstruktivisme. Dalam model PBL fokus pembelajaran ada pada masalah yang dipilih sehingga pebelajar mempelajari konsep-konsep yang berhubungan dengan masalah yang diangkat. Perpaduan model pembelajaran problem based learning dan green chemistry akan lebih maksimal jika siswa dipastikan memahami dan memaknai pembelajaran. Salah satu indikasinya yaitu siswa mampu menyampaikan apa yang telah diperolehnya setelah proses belajar baik secara lisan atau tulisan. Shizuo (2011) menggunakan lembar Study History Sheet (SHS) untuk menuliskan pemahaman siswa tentang polusi udara. Siswa menuliskan kesimpulan pembelajaran ke dalam lembar SHS untuk setiap pertemuan. Mencatat (merangkum) akan meningkatkan kemampuan daya ingat seseorang (De Porter, 2004:146).

Salah satu bab kimia di SMA adalah kelarutan dan hasil kali kelarutan. Dalam materi kelarutan dan hasil kali kelarutan membahas kelarutan dari senyawa-senyawa kimia. Kandungan senyawa-senyawa tertentu didalam air akan menentukan kualitas air. Kuantitas yang berlebihan dari suatu komponen berupa senyawa dalam air juga dapat menurunkan kualitas air yang akan memperparah terjadinya polusi atau pencemaran air. Dengan demikian materi kelarutan dan hasil kali kelarutan ini erat kaitannya dengan kehidupan sehari-hari dan harus dipelajari dengan pembelajaran yang tepat agar bermakna bagi siswa.

\section{METODE}

Rancangan penelitian yang digunakan yaitu rancangan eksperimensemu (Quasy Exsperimental Design) dengan post test only control group design. Rancangan eksperimen semu 
digunakan untuk membandingkan prestasi belajar siswa dalam pembelajaran antara kelas kontrol dan kelas eksperimen.Sebelum kelas eksperimen dan kelas kontrol diberikan perlakuan, dilakukan uji kesamaan rata-rata kemampuan awal siswa. Sampel penelitian terdiri dari kelas XI IPA 2 sebagai kelompok eksperimen dengan menerapkan study history sheet (SHS)-problem based learning dan kelas XI IPA 1 sebagai kelas kontrol dengan menerapkan model pembelajaran problem based learning.

Instrumen yang digunakan dalam penelitian meliputi instrumen perlakuan dan instrumen pengukuran. Instrumen perlakuan yang digunakan adalah Silabus yang digunakan pada kelas eksperimen dan silabus yang digunakan kelas kontrol, rencana pelaksanaan pembelajaran kelas eksperimen dan rencana pelaksanaan pembelajaran kelas kontrol, bahan ajar kelas eksperimen (bandout, worksheet, referensi, study history sheet) dan bahan ajar kelas kontrol (handout, worksheet, referensi). Instrumen pengukuran merupakan instrumen yang digunakan untuk mengukur/mencari data dalam penelitian. Instrumen pengukuran dalam penelitian ini meliputi lembar observasi, lembar tes kognitif dan angket.

Terdapat lima macam data yang akan dianalisis, yaitu data kemampuan awal siswa, prestasi belajar, data angket, dan keterlaksanaan pembelajaran. Data kemampuan awal dan data prestasi belajar siswa dianalisis dengan analisis statistik, sedangkan data angket, dan keterlaksanaan pembelajaran hanya dianalisis dengan menggunakan analisis deskriptif.

\section{HASIL}

\section{Keterlaksanaan Pembelajaran Kelas Kontrol dan Kelas Eksperimen}

Keterlaksanaan pembelajaran dengan model pembelajaran Problem Based Learning untuk kelas kontrol dan keterlaksanaan pembelajaran dengan model pembelajaran Problem Based Learning-SHS bahan ajar berbasis Green Chemistry untuk kelas eksperimen diperoleh dari penilaian obeserver selama pelaksanaan kegiatan pembelajaran berlangsung. Rencana Pelaksanaan Pembelajaran (RPP) yang digunakan dijelaskan secara rinci pada Lampiran 2 dan 4. Persentase keterlaksanaan pembelajaran untuk kelas kontrol dan untuk kelas eksperimen dapat dilihat pada Tabel 1.

\section{Deskripsi Data Kemampuan Awal Siswa}

Data kemampuan awal siswa pada kelas eksperimen dan kelas kontrol diperoleh dari nilai UTS (Ujian Tengah Semester). Data kemampuan awal siswa dapat dilihat pada Tabel 2.

\section{Analisis Data Kemampuan Awal Siswa}

Analisis data kemampuan awal siswa dilakukan untuk mengetahui apakah dua kelas yang digunakan untuk penelitian memiliki kemampuan yang sama. Analisis data menggunakan Independent Sample t-Test dengan bantuan program SPSS 16.0 for Windows. Sebelum dilakukan analisis Independent Sample t-Test, perlu dilakukan prasyarat analisis yaitu, uji normalitas dan homogenitas. Hasil uji prasyarat analisis diperoleh bahwa data 
kemampuan awal siswa kelas eksperimen dan kelas kontrol mempunyai sebaran yang normal dan varian yang homogen.

Pada Tabel 3 diperoleh hasil uji kemampuan awal siswa memiliki nilai signifikansi lebih dari 0,05 yakni sebesar 0,089. Dengan demikian dapat disimpulkan bahwa tidak ada perbedaan yang signifikan antara kemampuan awal siswa kelas eksperimen dengan kelas kontrol.

Tabel 1. Persentase Keterlaksanaan Pembelajaran di Kelas Kontrol dan Kelas Eksperimen

\begin{tabular}{ccc}
\hline Rencana Pelaksanaan & \multicolumn{2}{c}{ Keterlaksanaan Proses Pembelajaran } \\
\cline { 2 - 3 } Pembelajaran (RPP) & Kelas Kontrol (\%) & Kelas Eksperimen (\%) \\
\hline 1 & 84 & 88,46 \\
2 & 88,46 & 85,19 \\
3 & 88,89 & 90 \\
4 & 85,71 & 90 \\
Rata-rata & 86,77 & 88,41 \\
\hline
\end{tabular}

Tabel 2. Data Kemampuan Awal Siswa Kelas Eksperimen dan Kelas Kontrol

\begin{tabular}{ccc}
\hline Deskripsi & Kelas Kontrol & Kelas Eksperimen \\
\hline Jumlah siswa & 32 & 33 \\
Nilai Tertinggi & 80 & 80 \\
Nilai Terendah & 65 & 64 \\
Nilai Rata-rata & 71,91 & 73,45 \\
Standar deviasi & 3,604 & 3,615 \\
\hline
\end{tabular}

Tabel 3. Hasil Uji Kesamaan Dua Rata-rataKemampuan Awal Siswa Kelas Eksperimen dan Kelas Kontrol

\begin{tabular}{cccc}
\hline Kelas & Nilai Rata-rata & Nilai Signifikansi & Kesimpulan \\
\hline Kontrol & 71,91 & 0,089 & Tidak terdapat perbedaan \\
Eksperimen & 73,45 & & \\
& & & \\
\hline
\end{tabular}

\section{Deskripsi Data Prestasi Belajar Siswa}

Data prestasi belajar siswa diperoleh dari nilai ulangan harian yang dilaksanakan di akhir pembelajaran materi kelarutan dan hasil kali kelarutan. Data prestasi belajar siswa dapat dilihat pada Tabel 4.

\section{Analisis Data Prestasi Belajar Siswa}

Analisis prestasi belajar siswa digunakan untuk mengetahui ada tidaknya perbedaan prestasi belajar siswa pada kelas kontrol dan kelas eksperimen. Analisis data menggunakan Independent Sample t-Test dengan bantuan program SPSS 16.0 for Windows. Sebelum dilakukan analisis Independent Sample t-Test, perlu dilakukan prasyarat analisis yaitu, uji normalitas dan homogenitas. Hasil uji prasyarat analisis diperoleh bahwa data prestasi belajar siswa kelas eksperimen dan kelas kontrol mempunyai sebaran yang normal dan varian yang homogen. 
Pada Tabel 5 diperoleh hasil prestasi belajar siswa memiliki nilai signifikansi kurang dari 0,05 yakni sebesar 0,040. Dengan demikian dapat disimpulkan bahwa ada perbedaan yang signifikan antara prestasi belajar siswa kelas eksperimen dengan kelas kontrol.

Tabel 4 Data Prestasi Belajar Siswa Kelas Eksperimen dan Kelas Kontrol

\begin{tabular}{ccc}
\hline Deskriptif & Kelas Kontrol & Kelas Eksperimen \\
\hline Mean & 75,50 & 78,79 \\
Jumlah Siswa & 32 & 33 \\
Nilai Tertinggi & 88 & 92 \\
Nilai Terendah & 68 & 68 \\
Standar deviasi & 5,725 & 6,818 \\
\hline
\end{tabular}

Tabel 5 Hasil Uji Hipotesis Prestasi Belajar Siswa Kelas Eksperimen dan Kelas Kontrol

\begin{tabular}{lcccl}
\hline \multicolumn{1}{c}{ Kelas } & Jumlah Siswa & Nilai Rata-rata & $\begin{array}{c}\text { Nilai } \\
\text { Signifikansi }\end{array}$ & Kesimpulan \\
\hline Kontrol & 32 & 75,50 & & $\begin{array}{l}\text { Terdapat perbedaan } \\
\text { hasil belajar siswa }\end{array}$ \\
Eksperimen & 33 & 78,79 & 0,040 & \\
\hline
\end{tabular}

\section{Deskripsi Nilai Afektif}

Kemampuan afektif siswa yang diukur pada penelitian ini adalah sikap peduli terhadap masalah pencemaran air. Data sikap peduli siswa pada masalah pencemaran air diperoleh dari hasil pengisian angket "sikap peduli pada masalah pencemaran air" yang diberikan kepada siswa kelas kontrol dan kelas eksperimen pada pertemuan terakhir.

Tabel 6 Persentase Siswa yang memiliki Sikap Peduli pada Masalah Pencemaran air

\begin{tabular}{ccc}
\hline \multirow{2}{*}{ No. Pernyataan } & \multicolumn{2}{c}{ Persentase Kepedulian Siswa (\%) } \\
\cline { 2 - 3 } & Kelas Kontrol & Kelas Eksperimen \\
\hline 1 & 68,75 & 66,67 \\
2 & 93,75 & 100 \\
3 & 93,75 & 90,91 \\
4 & 78,13 & 75,76 \\
5 & 93,75 & 96,97 \\
6 & 90,63 & 100 \\
7 & 93,75 & 93,94 \\
8 & 90,63 & 96,97 \\
9 & 93,75 & 93,94 \\
10 & 100 & 100 \\
\hline Rata-rata & 89,69 & 91,52 \\
\hline
\end{tabular}

Berdasarkan Tabel 6 dapat diketahui bahwa rata-rata nilai afektif kelas kontrol dan kelas eksperimen mengalami peningkatan dari pertemuan pertama sampai pertemuan kelima. Rata-rata nilai afektif kelas eksperimen lebih tinggi daripada kelas kontrol. 


\section{Hubungan Rata-rata Nilai SHS dengan Hasil Belajar Kognitif}

Grafik hubungan rata-rata nilai $S H S$ siswa dengan hasil belajar kognitif disajikan pada Gambar 1. Hubungan korelasi antara rata-rata nilai SHS dan hasil belajar kognitif dicari menggunakan rumus korelasi Product Moment dengan bantuan Microsoft Office Excel 2007. Koefisien korelasi yang didapatkan sebesar 0,54 dengan kriteria hubungan korelasi kuat. Dengan demikian dapat disimpulkan bahwa semakin tinggi nilai SHS siswa, maka semakin tinggi pula hasil belajar siswa.

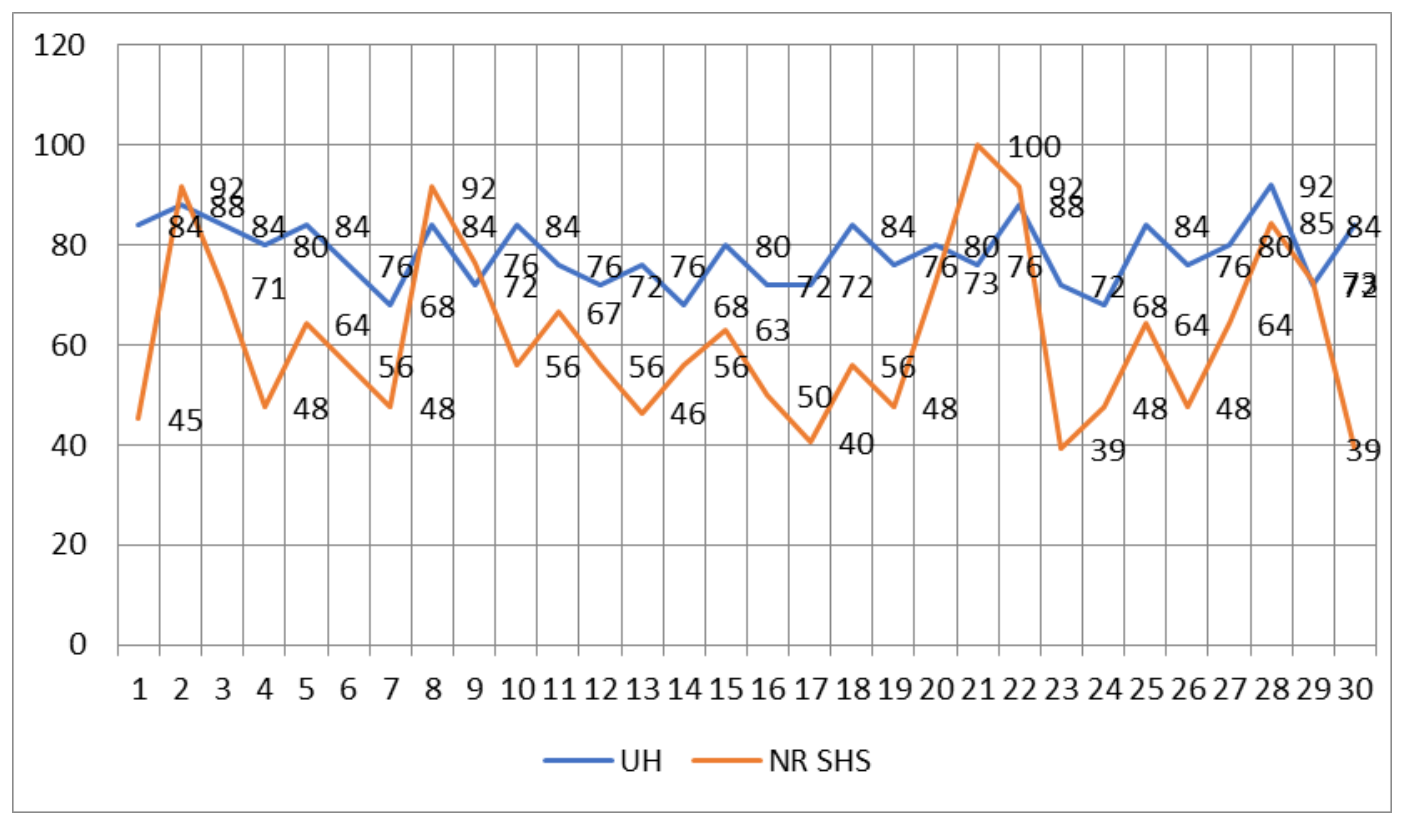

Gambar 1. Grafik Hubungan Rata-rata Nilai SHS dengan Hasil Belajar Kognitif Siswa

\section{PEMBAHASAN}

Pelaksanaan Pembelajaran Menggunakan Multimedia pada Strategi Pembelajaran Timbal Balik pada Kelas Eksperimen dan Strategi Pembelajaran Timbal Balik pada Kelas Kontrol

Secara keseluruhan pembelajaran terlihat siswa masih bingung dalam mengimplementasikan tahapan demi tahapan. Persentase keterlaksanaan pembelajaran pada kelas eksperimen 88,46\% dan kelas kontrol sebesar 84\%. Sehingga dapat disimpulkan secara keseluruhan keterlaksanan pembelajaran pada pertemuan pertama ini dapat berlangsung dengan sangat baik. Pertemuan kedua pada fase menyajikan hasil diskusi, siswa dari kelompok lain kurang aktif menyampaikan pendapat dan bertanya. Hal ini menyebabkan guru harus secara aktif memancing siswa untuk berpartisipasi dalam diskusi kelas. Persentase keterlaksanaan pembelajaran pada kelas eksperimen $85,19 \%$ dan kelas kontrol sebesar 88,46\%. Sehingga dapat disimpulkan secara keseluruhan keterlaksanan pembelajaran pada pertemuan pertama ini dapat berlangsung cukup lancar.

Pertemuan ketiga siswa secara keseluruhan secara aktif bekerja dalam kelompok dan berdiskusi tentang hasil praktikum penambahan ion senama. Namun karena 
keterbatasan waktu menyebabkan diskusi kelas tentang hasil praktikum tidak berjalan sesuai yang direncanakan dalam RPP. Siswa hanya berkesempatan untuk menyajikan hasil praktikum dari masing-masing kelompok saja. Pada kelas eksperimen maupun kelas kontrol, siswa sudah semakin terlihat aktif dalam berdiskusi dan bekerja sama secara kelompok dalam melakukan praktikum. Pada fase ini guru juga bisa menilai karakter dan ketrampilan siswa saat diskusi dalam kelompok. Pada pertemuan keempat Siswa terlihat lebih bersemangat dalam pembelajaran dengan metode praktikum jika dibandingkan dengan teori dikelas. Hal ini disebabkan siswa yang jarang melakukan praktikum langsung untuk materi pembelajaran sebelumnya. Dengan praktikum siswa dapat secara langsung mempelajari terjadinya pengendapan. Sehingga siswa lebih aktif dalam pembelajaran dan lebih mudah memahami materi.

Pada akhir pembelajaran siswa diminta untuk mengisi angket tentang pencemaran air. Selain itu guru meminta siswa untuk menuliskan 3 kalimat tentang pencemaran air pada kolom "sesudahpembelajaran" pada lembar SHS dan kolomkesan dan pesan tentang pembelajaran dengan menggunakan SHS-Problem Based Learning. Terlihat peningkatan pengetahuan siswa tentang pencemaran air. Hal ini dapat dilihat jika membandingkan antara kolom "sebelum pembelajaran" dan kolom "setelah pembelajaran" pada lembar SHS siswa. Siswa menuliskan pendapat yang lebih luas dan mendalam tentang pencemaran air pada kolom "setelah pembelajaran".

Grafik keterlaksanaan proses pembelajaran kelas yang dibelajarkan dengan model pembelajaran problem based learning-shs bahan ajar berbasis green chemistry dan kelas yang dibelajarkan dengan model pembelajaran problem based learning dapat dilihat pada Gambar 2. Secara keseluruhan keterlaksanaan pembelajaran berjalan dengan baik. Ratarata keterlaksanaan pembelajaran di kelas eksperimen sebesar 88,41\% dan rata-rat keterlaksanaan pembelajaran di kelas kontrol sebesar $86,77 \%$.

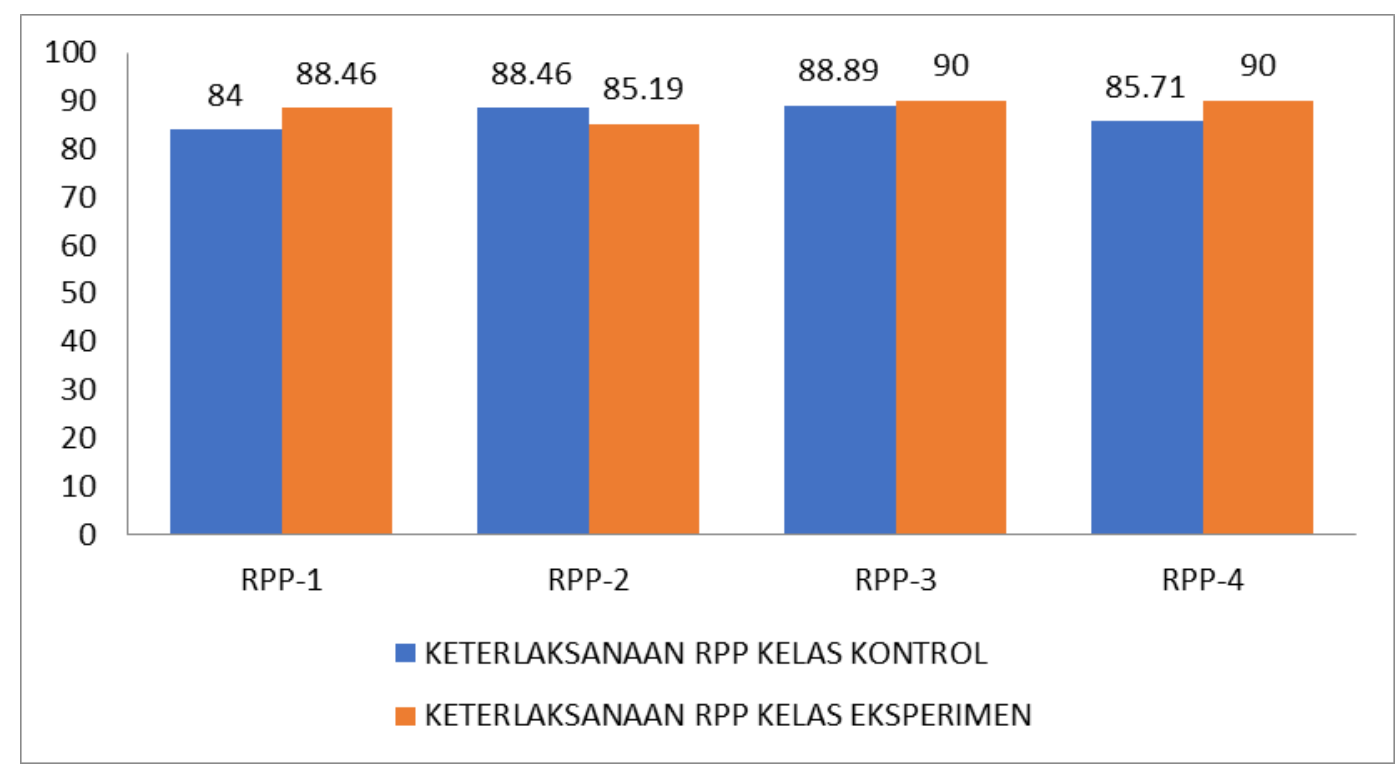

Gambar 2 Keterlaksanaan Proses Pembelajaran Kelas yang Dibelajarkan dengan Model Pembelajaran Problem Based Learning-SHS Bahan Ajar Berbasis Green Chemistry dan Kelas yang Dibelajarkan dengan Model Pembelajaran Problem Based Learning 
Dari hasil pengisian SHS yang telah dilakukan selama pembelajaran, diketahui pengetahuan siswa "pencemaran air" yang ditulis siswa pada kelas eksperimen memiliki perbedaan sebelum dan sesudah pembelajaran. Hal ini dapat diketahui dari hasil tulisan siswa yang lebih menjabarkan tentang pencemaran air pada kolom tersebut. Hal ini berbeda dengan kolom sebelum pembelajaran dimana siswa hanya menuliskan kalimat singkat tentang pencemaran air. Dalam kolom kesan, siswa menuliskan kesannya lebih termotivasi, lebih tertarik dalam pembelajaran karena semua rangkuman tersaji dalam 1 lembar SHS. Bahan ajar untuk kelas eksperimen tersebut disajikan dalam bentuk HandOut, Referensi 1 dan Worksheet 1 tentang polutan surfaktan, Referensi 2 dan Worksheet 2 tentang air sadah, Referensi 3 dan Worksheet 3 tentang air berklorin, Referensi 4 dan Worksheet 4 tentang Fe Besi, dan lembar Study History Sheet (SHS). Sedangkan untuk kelas kontrol disajikan dalam bentuk HandOut, Referensi 1 dan Worksheet 1 tentang polutan surfaktan, Referensi 2 dan Worksheet 2 tentang air sadah, Referensi 3 dan Worksheet 3 tentang air berklorin, Referensi 4 dan Worksheet 4 tentang Fe Besi. Jadi, perbedaan kelas kontrol dan eksperimen terletak pada SHS dan Konsep green chemistry.

\section{Hasil Belajar Materi Sistem Kelarutan dan Hasil Kali Kelarutan}

Uji hipotesis hasil belajar kognitif menunjukkan bahwa terdapat perbedaan hasil belajar kognitif antara siswa pada kelas eksperimen yang dibelajarkan menggunakan Model pembelajaran Problem Based Learning (PBL)-Study History Sheet (SHS) Bahan Ajar Berbasis Green Chemistry dengan siswa pada kelas kontrol yang menggunakan model pembelajaran Problem Based Learning. Rata-rata hasil belajar kognitif siswa kelas eksperimen sebesar 78,79 sedangkan kelas kontrol sebesar 75,50. Setelah dianalisis menggunakan uji- $t$ dua pihak diperoleh nilai signifikansi sebesar 0,040 . Nilai signifikansi kurang dari 0,05 sehingga dapat disimpulkan bahwa terdapat perbedaan yang signifikan untuk hasil belajar. Dengan menggunakan lembar Study History Sheet, siswa difokuskan untuk mencari inti dari masalah-masalah dalam worksheet dan menuliskannya pada kotak-kotak yang telah disediakan pada lembar SHS. Secara individu, siswa menuangkan idenya dan menyusun kalimat sesuai dengan pemahamannya untuk membuat ringkasan pada lembar SHS. Hal ini sesuai dengan penjelasan Shizuo, et al.(2011: 67) bahwa setiap kotak dalam lembar penilaian Study History Sheet tidak cukup besar sehingga siswa harus memilih kata dan kalimat untuk dibuat ringkasan. Dengan cara seperti ini, siswa lebih mudah untuk mengingat materi-materi yang telah dipelajari dan mengetahui perubahan pengetahuan yang dimilikinya. Hal ini sesuai dengan penjelasan Shizuo, et al.(2011: 68) bahwa penggunaan lembar Study History Sheet (SHS) dalam pembelajaran dapat membantu siswa mengetahui kegiatan sebelumnya dan lebih mengetahui perubahan pengetahuan yang dimilikinya.

Siswa yang dibelajarkan dengan lembar Study History Sheet pada model pembelajaran Problem Based Learning lebih antusias dalam memberikan tanggapan dan menyumbangkan idenya karena pikiran siswa lebih terkonsep setelah merangkum jawabannya pada lembar Study History Sheet (SHS). Hal tersebut menyebabkan siswa lebih mudah dalam mengikuti diskusi. Sehingga dapat disimpulkan bahwa penggunaan lembar Study History Sheet selain meningkatkan kemampuan kognitif siswa, juga mampu meningkatkan kemampuan afektif siswa. 


\section{KESIMPULAN}

Keterlaksanaan pembelajaran dengan menggunakan model pembelajaran Problem Based Learning untuk kelas kontrol maupun pembelajaran dengan menggunakan Problem Based Learning (PBL)-Study History Sheet (SHS) Bahan Ajar Berbasis Green Chemistry untuk kelas eksperimen berlangsung dengan baik dan sudah sesuai dengan RPP. Ratarata persentase keterlaksanaan pembelajaran di kelas kontrol sebesar 89\% sedangkan rata-rata persentase keterlksanaan pembelajaran di kelas eksperimen sebesar $90 \%$.

Ada Pengaruh Penggunaan Model pembelajaran Problem Based Learning (PBL)Study History Sheet (SHS) Bahan Ajar Berbasis Green Chemistry Pada Materi Kelarutan dan Hasil Kali Kelarutan terhadap Prestasi Belajar kognitif siswa kelas XI SMA Negeri 10 Malang. Prestasi belajar kognitif siswa kelas eksperimen lebih tinggi $(\bar{x}=79)$ dibandingkan dengan prestasi belajar kognitif siswa pada kelas kontrol $(\bar{x}=76)$.

Ada Pengaruh Penggunaan Model pembelajaran Problem Based Learning (PBL)Study History Sheet (SHS) Bahan Ajar Berbasis Green Chemistry Pada Materi Kelarutan dan Hasil Kali Kelarutan terhadap Prestasi Belajar afektif siswa kelas XI SMA Negeri 10 Malang. Hal tersebut dibuktikan dengan hasil pengisian angket didapatkan data persentase rata-rata sikap kepedulian siswa untuk kelas kontrol sebesar $90 \%$, sedangkan kelas eksperimen sebesar $92 \%$.

Dari hasil penelitian yang telah dilakukan, maka saran yang diberikan adalah Bagi guru yang ingin menerapkan Problem Based Learning (PBL)-Study History Sheet (SHS) Bahan Ajar Berbasis Green Chemistry hendaknya lebih mempersiapkan dahulu perangkat pembelajarannya secara lebih matang. Pembelajaran menggunakan bahan ajar berbasis green chemistry memerlukan waktu yang cukup lama untuk menyelesaikan tahapan pembelajaran secara maksimal, untuk itu disarankan dapat mengelola waktu dengan baik agar materi yang disampaikan dapat diterima siswa secara menyeluruh tanpa mengesampingkan materi inti dalam materi kelarutan dan hasil kali kelarutan.

\section{DAFTAR RUJUKAN}

De Porter, Bobbi \& Mike Hernacki. 2004. Quantum Learning. Bandung: Kaifa.

Hjeresen, Dennis L., Schutt, David L., \& Boese, Janet M. 2000. Chemical Education Today. Green Chemistry and Education, 1544 (77) (online), (http://chem.edu.com), diakses tanggal 30 September 2013.

Mukaromah, Sugiharto, \& Saputro, Sulistyo. 2014. Efektivitas Pemberian Problem Posing pada Model Pembelajaran TGT (Teams Games Tournaments) Terhadap Hasil Belajar Kimia pada Materi Pokok Kelarutan dan Hasil Kali Kelarutan Kelas XI Semester 2 SMA Negeri 4 Surakarta Tabun Pelajaran 2013/2014, (Online). Vol.3 no.4:41:50 (http://jurnal.fkip.uns.ac.id/index.php/kimia/article/viewfile/4463//3104) diakses 20 April 2017.

Shizuo, M.et al. 2011. Development and Practice of "Air Pollution" Educational Material Unit Aiming an Educatiun for Sustainable Development, 2011(6): 64-71. 